\title{
ASPECTOS DA ULTRA-ESTRUTURA DOS CECOS GÁSTRICOS DA LARVA DE ODONTOSCIARA SP. (DIPTERA: SCIARIDAE)
}

CARMINDA DA CRUZ LANDIM

REGINA LUCIA MORELLI SILVA DE MORAES'

\begin{abstract}
Ultrastructural features of the gastric caeca of Odontosciara $\mathrm{sp}$. are reported. The species has 4 lateral caeca connected with the anterior midgut at the level of the foregut junction. The epithelial cell features indicate protein synthesis, digested material absorption from the lumen and haemolymph material absorption. Those functions, however, do not seem to be very intense.
\end{abstract}

\section{INTRODUÇÃO}

O intestino médio, ou ventrículo dos insetos é, tanto na larva como no adulto, a porção do canal alimentar que apresenta menos diferenciações anatômicas. Geralmente apresenta-se como um tubo simples, porém, umas poucas vezes, como nos dípteros, encontra-se dividido em uma câmara anterior e numa posterior; outras vezes mostra divertículos laterais ou cecos.

Os cecos entéricos ou gástricos geralmente se apresentam como divertículos saculiformes ou tubulares, originando-se na união entre o intestino anterior e médio, em número variável.

Segundo Richards \& Davies (1979), o. número de cecos presentes nos insetos varia de 2 a 8 , estando presentes dois em certos dípteros e 8 nos culicídeos. Na larva de Rhynchosciara americana estão presentes 2 cecos (Ferreira e cols., 1981).

A ultra-estrutura do intestino médio dos insetos tem sido submetida a numerosas investigações (Beams \& Anderson, 1957; Bertram \& Bird, 1961; Priester, 1971; Hecker \& col., 1974; Noirot \& Noirot-Timothée, 1972; Gemetchu, 1974; Houk, 1977; Hecker, 1977; Davies, 1977; Ferreira e cols., 1981), mas muito pouco ou nada tem sido dito a respeito dos cecos.

Segundo Chapman (1972) os cecos nos ortópteros podem apresentar uma ligação alargada ou muito estreitada com o intestino médio. No primeiro caso o alimento penetra também nos cecos e no segundo caso não. De qualquer maneira tem sido determinada a presença de enzimas digestivos nos cecos (Evans \& Payne, 1964) as quais podem inclusive apresentar concentração diferente daquela encontrada no intestino médio. Ferreira \& Terra (1980) atribuem aos cecos de Rhynchosciara americana função na absorção do alimento digerido. Alguns autores acham que as células constituintes dos cecos são morfologicamente parecidas com as células oxínticas do estômago dos vertebrados (Chapman, 1972).

No presente trabalho apresenta-se um relato da ultra-estrutura das células dos cecos de um díptero, com a finalidade de contribuir para o conhecimento de uma parte do tubo digestivo dos insetos que é ainda desconhecida a esse nível e controvertida quanto à função.

\section{MATERIAL E MÉTODOS}

Cecos gástricos de larvas de Odontosciara sp. foram fixados em solução de glutaraldeído a $3 \%$ em tampão fosfato $0,08 \mathrm{M}, \mathrm{pH} 7,4$ durante 2 horas a $4^{\circ} \mathrm{C}$. As peças foram a seguir lavadas no tampão e pós-fixadas em tetróxido de ósmio a $1 \%$ no mesmo tampão durante 1 hora a $4^{\circ} \mathrm{C}$. Após nova lavagem no tampão procedeu-se a desidratação em série de etanóis de concentraçõès cres-

Departamento de Biologia, Instituto de Biociências de Rio Claro, UNESP, Rio Claro, SP. 
centes, tendo o material sido embebido e incluído em Epon 812, via óxido de propileno.

Secções ultra-finas foram obtidas com navalhas de vidro em ultramicrótomo Porter-Blum MT2. Estas foram contrastadas com acetato de uranila a $2 \%$ e citrato de chumbo preparado segundo Reinholds.

As secções foram examinadas e fotografadas em microscópio eletrônico Zeiss EM9, série 2.

\section{RESULTADOS}

$\mathrm{Na}$ espécie estudada verificou-se a presença de 4 cecos (Fig. 1a) constituídos por túbulos finos e longos que desembocam lateralmente na passagem do intestino anterior para o médio.

As células epiteliais que formam a parede destes túbulos têm a forma de domo, projetando-se a parte apical para a luz e ficando os contatos celulares restritos às regiões baixas das células (Fig. 1b). O lúmen dos túbulos apresenta-se praticamente fechado e sem nenhum conteúdo aparente. Microvilosidades curtas distribuem-se por toda a superfície livre das células. $\mathrm{O}$ aspecto que assemelha estas células às oxínticas do estômago é justamente o fato de as microvilosidades se aprofundarem na região dos contatos celulares (Fig. 1b).

Além das células epiteliais, fazem parte da parede dos túbulos finas fibras musculares dispostas em duas camadas: a mais interna circular e a externa longitudinal (Figs. $1 \mathrm{~b}$ e $2 \mathrm{~b}$ ). Uma lâmina de tecido conjuntivo amorfo fecha $\mathrm{o}$ contorno do túbulo (Figs. $1 \mathrm{~b}$ e $2 \mathrm{~b}$ ) externamente.

As células epiteliais dos cecos, pelo menos na fase estudada, não apresentam características morfológicas de caráter muito especial.

Conforme já foi dito, ao longo de toda a superfície apical livre ocorrem microvilosidades curtas, dispostas regularmente e sustentadas por microfilamentos longitudinais (Figs. 1b, 2a, 3a e b3). Nota-se, especialmente nas figuras $1 \mathrm{~b}$ e $3 \mathrm{a}$, que abaixo destas ocorre uma trama apical destes mesmos microfilamentos, o que é indicado pela zona clara, livre de orgânulos celulares imediatamente abaixo das microvilosidades. Ainda na porção apical da célula notam-se grânulos de alta densidade eletrônica, provavelmente constituídos por secreção celular, alguns vacúolos e algumas mitocôndrias (Figs. 1b, 2a, 3a e b) além de retículo granular e ribossomos livres.

$\mathrm{Na}$ porção basal, a célula apresenta uma lâmina basal com as características usuais (Fig. 2b) e formações resultantes de invaginações da membrana plásmica, dando origem principalmente a vesículas (Fig. 2b). Estas invaginações não são especialmente proeminentes, e embora haja mitocôndrias na região, não se nota associação consistente entre ambas as estruturas. A membrana plásmica basal apresenta ao longo de toda sua extensão pontos de maior densidade, que provavelmente representam reforços na sua adesão com a lâmina basal.

A porção média da célula contém o núcleo, que é politênico (Fig. 4a), retículo endoplasmático granular, mitocôndrias alongadas, secreção, vacúolos com conteúdo electronlúcido e zonas de Golgi (Figs. 1b, 2a, 4a).

Apesar da divisão da célula em regiões, feita para efeito de descrição, e embora ela apresente uma polaridade bem definida, o zoneamento descrito não é muito evidente.

O Golgi apresenta-se como zonas vesiculosas em cujas proximidades se encontram agrupados grânulos densos, tidos como secreção (Fig. 2a). A secreção apresenta-se eletronicamente muito densa e acumula-se sob a forma de grânulos pequenos nas zonas de Golgi (Fig. 2a) ou sob forma de grânulos maiores na porção apical das células (Figs. 3a e b). São observadas, às vezes, vesículas destacando-se das cisternas do retículo, que ainda apresentam ribossomos na parede e conteúdo de densidade eletrônica média (Fig. 3a).

A estrutura celular ao longo do comprimento do ceco não mostra diferenciações, mas na porção proximal há uma zona de transição em que as microvilosidades ainda não se encontram completamente formadas (Figs. 4b e c). Nesta zona nota-se a presença de uma cutícula fina limitando o bordo apical da célula epitelial e abaixo desta, vacúolos regularmente dispostos, 


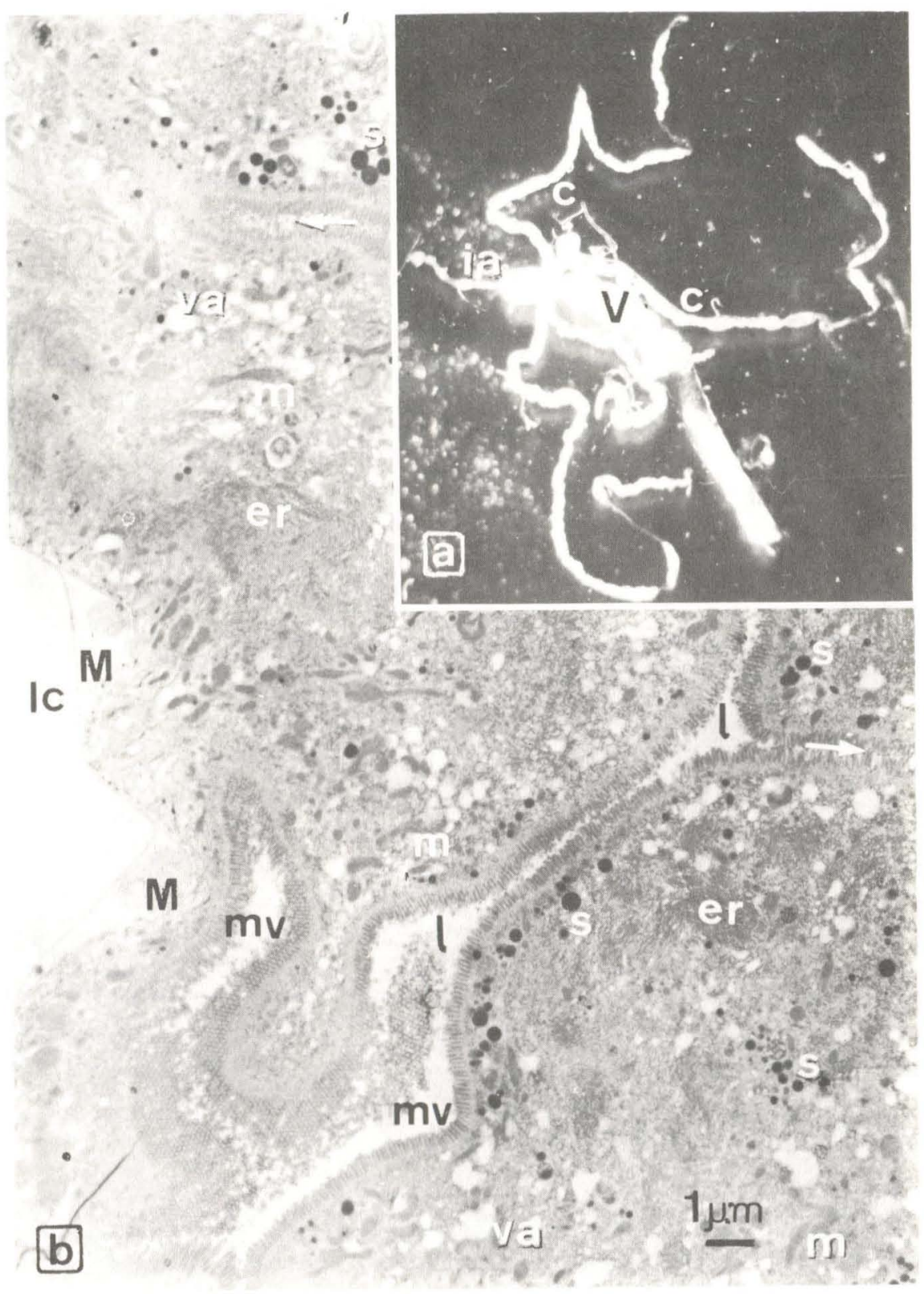

Fig. la - Aspecto dos cecos gástricos. b - Micrografia eletrônica mostrando a organização geral do ceco. As setas indicam as porções da superfície das células epiteliais aprofundadas na região dos contatos celulares. $\mathrm{ia}=$ intestino anterior; $\mathrm{V}=$ ventrículo; $\mathrm{c}=\operatorname{cecos} ; 1=$ lúmen; $\mathrm{M}=$ células musculares; $\mathrm{mv}=$ microvilosidades; $\mathrm{s}=$ secreção; $\mathrm{er}=$ retículo endoplasmático granular; $\mathrm{m}=$ mitocôndrias; $\mathrm{lc}=$ lâmina conjuntiva; va = vacúolos. 


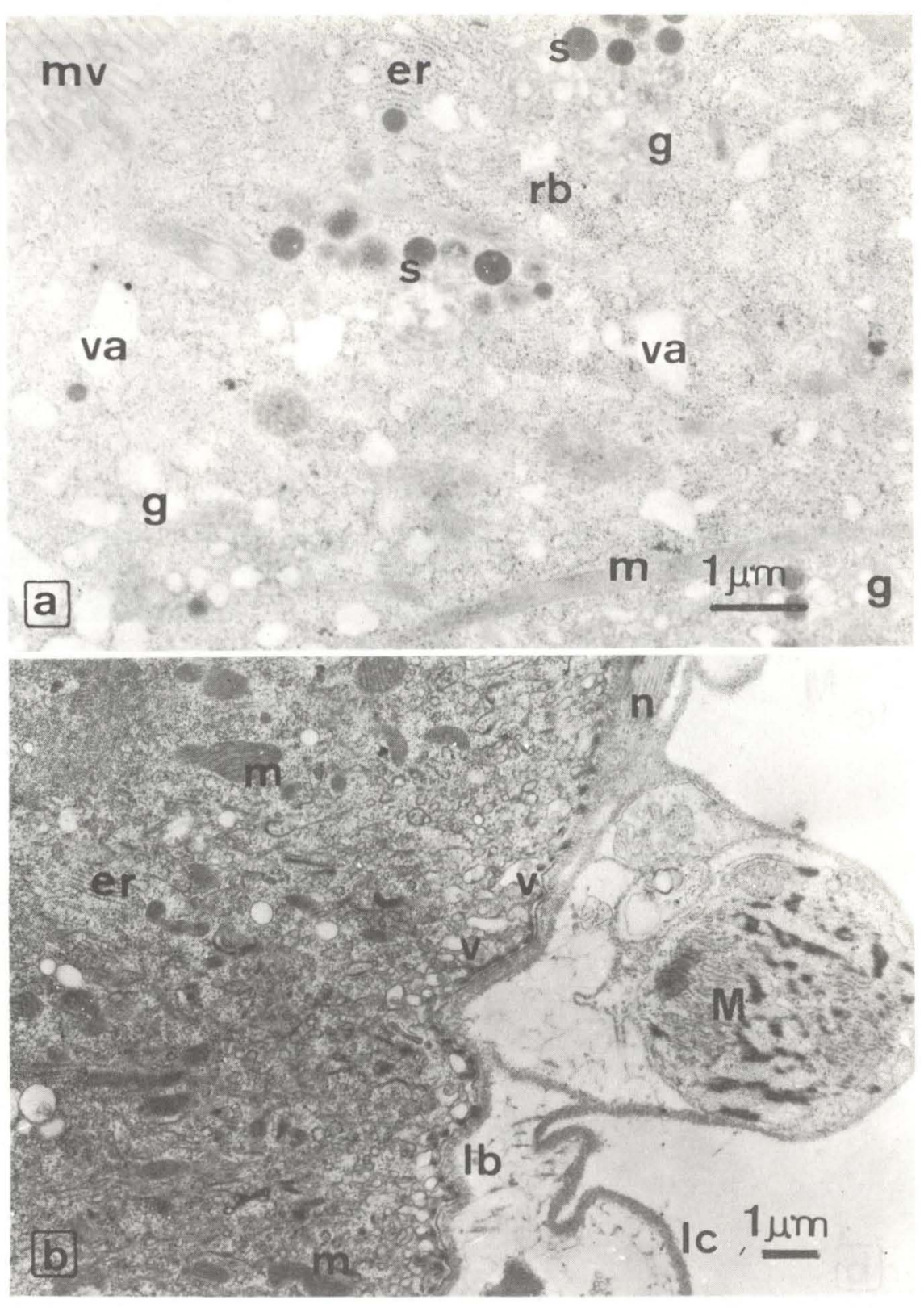

Fig. 2a - Porção médio-apical de uma célula epitelial mostrando várias zonas de Golgi (g). b - Porção basal de uma célula epitelial mostrando invaginações da membrana plásmica basal com formação de vesículas (v). Notar os pontos densos à longo da membrana plásmica. mv $=$ microvilosidades; $\mathrm{s}=$ secreção; er = retículo endoplasmático granular; $\mathrm{rb}=$ ribossomos livres; $\mathrm{m}=$ mitocôndrias; $\mathrm{va}=$ vacúolos; $\mathrm{lb}=$ lâmina basal; $\mathrm{lc}=$ lâmina conjuntiva; $\mathbf{M}=$ células musculares. 


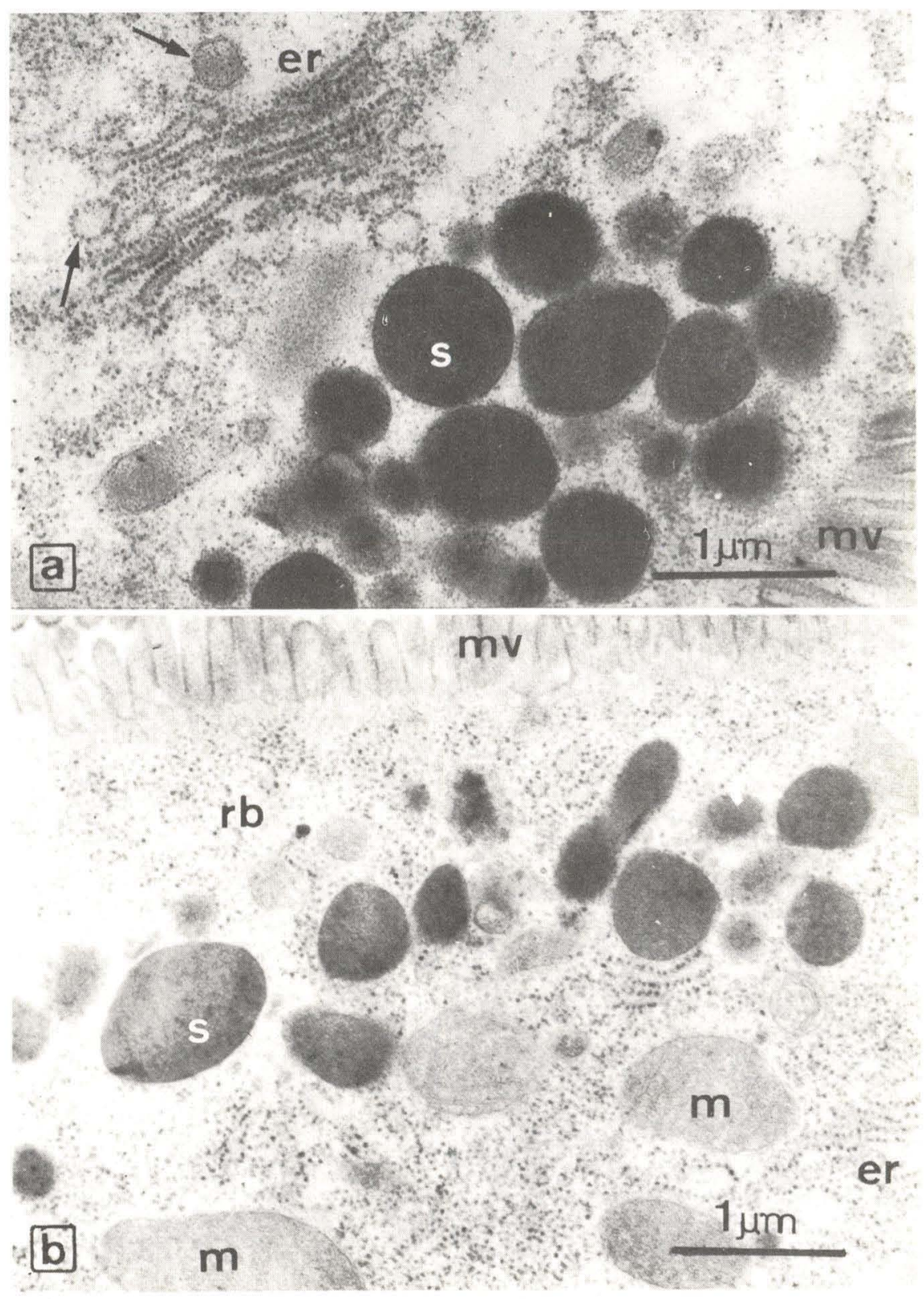

Fig. 3 - Aspectos da secreção (s) na porção apical das células. Notar em $a$ a formação de vesículas (setas) a partir de cisternas do retículo granular (er). $\mathrm{mv}=$ microvilosidades; $\mathrm{m}=$ mitocôndrias. 


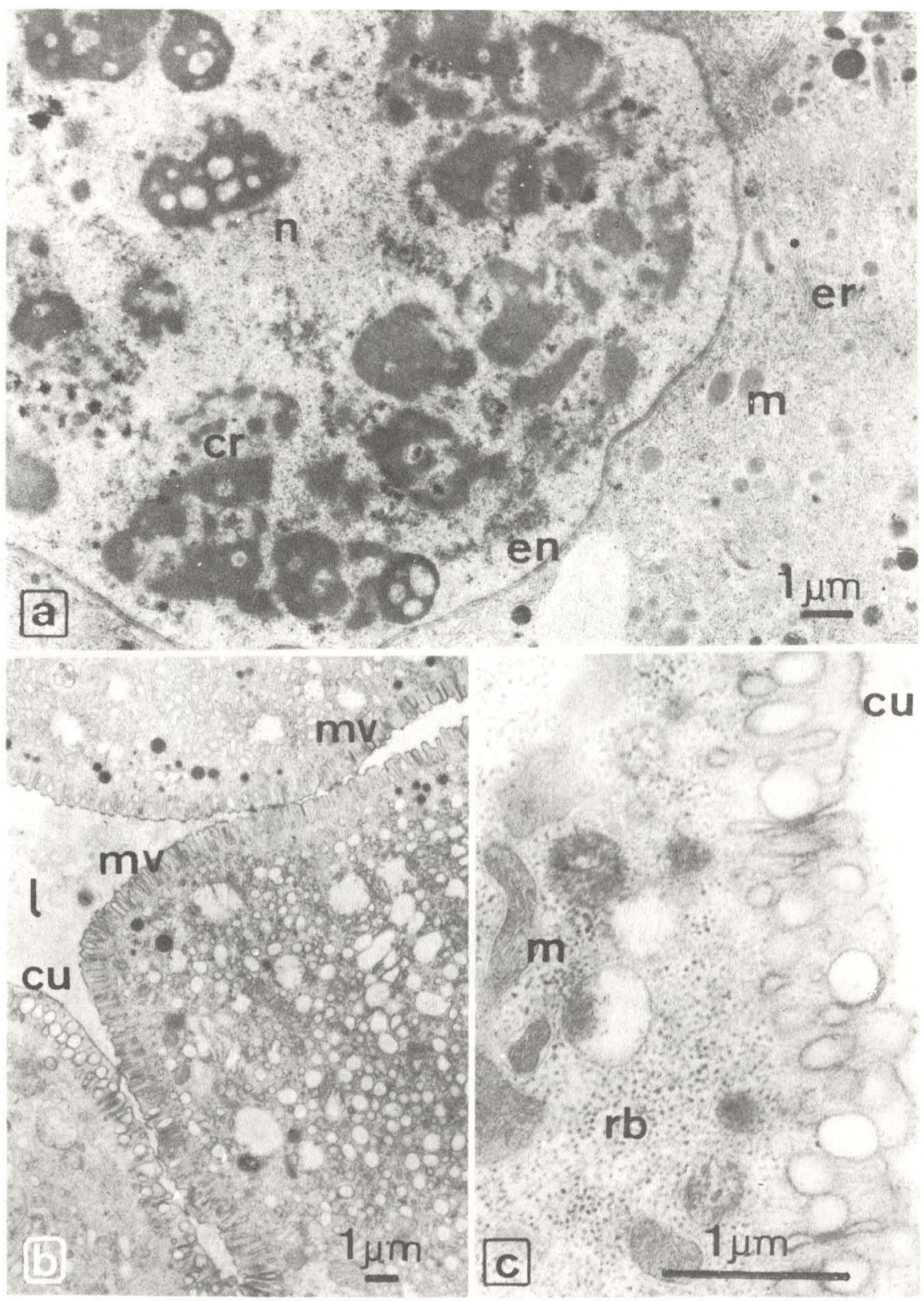

Fig. 4a - Aspecto do núcleo (n) mostrando cromossomos politênicos ( $\mathrm{cr}$ ). $4 \mathrm{~b}$ - Pequeno aumento mostrando a transição de um epitélio com cutícula (cu) para o epitélio dos cecos com microvilosidades (mv). 4c - Aspecto da diferenciação das microvilosidades. 
alguns esféricos e outros alongados, mas delimitando porções de hialoplasma. Estas individualizam-se em microvilosidades pela fusão da membrana dos vacúolos com a membrana apical da célula (Figs. 4b e c).

\section{DISCUSSÃO E CONCLUSÕES}

Conforme foi mostrado, a ultra-estrutura apresentada pelas células epiteliais dos cecos desta larva na fase estudada (a qual não foi determinada porque as larvas foram coletadas na natureza) não permite muitas especulações a respeito de sua função.

É evidente, pelo desenvolvimento do retículo endoplasmático granular e do Golgi, que se trata de uma célula secretora e que a secreção é, provavelmente, de natureza protéica. A própria estrutura e densidade dos grânulos parecem indicar essa natureza. Por outro lado, embora ocorram grânulos na porção apical da célula a sua eliminação não foi observada.

A presença de vacúolos com conteúdo claro poderia ser indicativa da ocorrência de absorção de material por estas células; contudo, não se verifi. cam vesículas micropinocíticas na parte apical de cuja fusão pudessem se originar e que indicariam a absorção de seu conteúdo a partir da luz. Dada a presença de espaços abertos, de invaginações da membrana plásmica basal e da formação de vesículas nesta região (Figs. $1 \mathrm{~b}$ e $2 \mathrm{~b}$ ), parece mais adequado admitir absorção a partir da hemolinfa do material presente nos vacúolos.

De acordo com Ferreira \& Terra (1980) os cecos seriam locais da digestão final dos alimentos e de uua absorção.

A ocorrência de uma luz estreita e aparentemente vazia indica que o alimento ingerido pela larva não entra nos cecos; aliás, segundo Ferreira e cols. (1981) apenas o conteúdo endoperitrófico (material que já atravessou a membrana peritrófica) penetra nos cecos de Rhynchosciara americana. A presença de microvilosidades é sempre considerada como indicativa de função absortiva por parte das células que as apresentam. Portanto, neste particular, as células apresentam características morfológicas que as capacitam para a função postulada pelos autores citados acima, somente que o material é absorvido sem provocar alterações morfológicas ao nível do exame feito, como é o caso de material completamente digerido.

Pode-se concluir da morfologia apresentada pelas células epiteliais que provavelmente estas apresentem função secretora de material de natureza protéica, que absorvem material digerido a partir da luz e material da hemolinfa através de invaginações da membrana plásmica, sem contudo desempenhar essas funções de maneira muito acentuada.

\section{REFERENCIAS}

Beams, H. W. \& Anderson, E., 1957. Light and electron microscope studies on the striated border of the intestinal cells of insects. J. Morphol., 100: 601-619.

Bertram, D. S. \& Bird, R. G., 1961. Studies on mosquito-borne viruses in their vector. I. The normal fine structure of the midgut epithelium of adult female Aedes aegypti L. and the functional significance of its modifications following a bloodmeal. Trans. R. Soc. trop. Med. Hyg., 54: 362-365.

Chapman, R. F., 1972. The insects: structure and funcion. The English University Press Ltd. London.

Davies, I., 1977. The effect of diet on the ultrastructure of the midgut cells of Nasonia vitripennis (Walk.) (Insecta: Hymenoptera) at various ages. Cell Tiss. Res., 184:529-538.

Evans, W. G. \& Payne, D. W., 1964. Carbohydrases of the alimentary tract of desert locust, Schistocerca gregaria Forsk. J. Insect Physiol., 10:657-674.

Ferreira, C. \& Terra, W. R., 1980. Intracellular distribution of hydrolases in midgut caeca cells from an insect with emphasis on plasma membranebound enzymes. Comp. Biochem. Physiol., 66B: 467-473. 
Ferreira, C.; Ribeiro, A. F. \& Terra, W. R., 1981. Fine structure of the larval midgut of the fly Rhynchosciara and its physiological implications. J. Insect Physiol., 27: 559-570.

Gemetchu, T., 1974. The morphology and fine structure of the midgut and peritrophic membrane of the adult female. Phlebotomus longipes Parrot and Martin (Diptera: Psychodidae). Ann. Trop. Med. Hyg., 68: 111-124.

Hecker, H.; Brun, R.; Reinhardt, C. \& Buni, P. H., 1974. Morphometric analysis of the midgut of female Aedes aegypti L. (Insecta, Diptera) under various physiological conditions. Cell Tiss. Res., 152: 31-49.

Hecker, H., 1977. Structure and function of midgut cells in Culicidae mosquitoes (Insecta, Diptera). Cell Tiss. Res., 184: 321-341.

Houk, E. J., 1977. Midgut ultrastructure of Culex tarsalis (Diptera Culicidae) before and after a bloodmeal.. Tissue and Cell, 9: 103-118.

Noirot, Ch. \& Noirot-Timothée, C., 1972. Structure fine de la bordure en brosse de l'intestin chez les insects. J. Microscopie, L3: 85-87.

Priester, W., 1971. Ultrastructure of the midgut epithelial cells in the fly Calliphora erytrocephala. J. Ultrastruct. Res., 36: 783-805.

Richards, O. W. \& Davies, R. G., 1979. Imms General textbook of Entomology, vol. 1: Structure, Physiology and Development. Science Paperbacks, Chapman and Hall, London. 